International Journal of Economics, Business and Management Research

Vol. 6, No.01; 2022

ISSN: $2456-7760$

\title{
Do Official Development Assistance Affect Formation of Human Capital? Evidence from Cemac Countries
}

\author{
Nadine Ekamena Ntsama ${ }^{1}$, Adèle Micheline NGO BILONG ${ }^{2}$, Samaki Béatrice FANTA ${ }^{3}$ \\ ${ }^{1}$ Maroua University, Faculty of Economics and Management, \\ 46, Maroua, Cameroon \\ ${ }^{2}$ Faculty of Mines and Petroleum Industries, Maroua University, \\ 08, Kaele, Cameroon \\ ${ }^{3}$ Maroua University, Faculty of Economics and Management, \\ 46, Maroua, Cameroon
}

doi: 10.51505/IJEBMR.2022.6104

URL: http://dx.doi.org/10.51505/IJEBMR.2022.6104

\begin{abstract}
Education and health are two important aspects of a human being's life which form his human capital. The objective of our work is to assess the effect of Official Development Assistance (ODA) on the formation of Human Capital in the CEMAC zone. To achieve this, we use an econometric model on panel data collected between 1994 and 2017. The estimate by the Generalized Moments Method shows that the ODA granted in the CEMAC zone significantly increases the literacy rate in the region area; likewise, an increase in ODA results in a small decrease in the death rate. The low impact of the aid felt in the formation of human capital therefore calls on the recipient countries to be more serious in monitoring the aid received and in directing this aid in promising areas.
\end{abstract}

Keywords: official development assistance, human capital formation; CEMAC

\section{Introduction}

Global economic progress has reduced the extreme poverty of the planet's inhabitants, although nearly half, or around 3.4 billion people, still face great difficulties in meeting their basic needs. According to a report published by the World Bank in 2017, poverty is concentrated today in sub-Saharan Africa, which in 2015, accounted for $90 \%$ of people living below the threshold of 1.9 dollars per day. In addition, there is still a lot of progress to be made in the areas of health and education, which still perform poorly compared to the rest of the world. In fact, despite the increase in school attendance, more than two in five adults cannot read or write and the level of education is very low. For example, three-quarters of grade 6 students in Malawi and Zambia read words but do not understand their meaning. The same is true for health outcomes where nearly two in five children suffer from chronic malnutrition and progress in vaccination campaigns and mosquito net distribution (to prevent malaria) is starting to slow.

"Official development assistance" (ODA) understood as the aid provided by states with the express aim of promoting economic development and improving living conditions in developing 


\section{International Journal of Economics, Business and Management Research}

Vol. 6, No.01; 2022

ISSN: $2456-7760$

countries was adopted by the DAC (Development Assistance Committee) of the OECD in 1969 as the benchmark for foreign aid. It remains the main source of funding for development assistance. ODA amounted to US \$ 152.8 billion in 2019, up 1.4\% in real terms from 2018, according to preliminary data collected from official development agencies. Bilateral ODA to Africa and the least developed countries increased by $1.3 \%$ and $2.6 \%$ respectively

The CEMAC zone, which includes six underdeveloped countries (Cameroon, Equatorial Guinea, Gabon, Central African Republic, Congo, Chad), also receive assistance from outside and these countries have joint operations including: the same currency (FCFA), trade,... The question that can be asked is: what is the effect of ODA on the formation of human capital in the CEMAC zone? The general objective of this study is therefore to analyze the effect of ODA granted in the CEMAC zone on the formation of human capital. Specifically, the aim is to analyze the effect of ODA granted in the CEMAC zone on access to education on the one hand and on access to health care on the other.

\section{Theoretical background}

- Relationship between official development assistance and human capital formation

Adam Smith (1776), in his work "The Wealth of Nations" already mentioned the role of human capital in the creation of wealth. He stressed that improving the skills of workers would lead to an increase in their productivity, allowing for increased production of wealth. Thus, more skilled workers must receive higher wages to compensate for their incurred expenses and the shortening of their working life cycle. Several economic theories including the theory of endogenous growth developed by Romer (1990) also present human capital as one of the factors of growth. Much has been written on the impact of aid on growth, but there is only a few writings on the impact of aid on very distinct things such as education, health,.... Some authors have shown a significant positive effect of aid on growth (Hansen and Dalgaard, 2001). On the other hand, they have shown that aid has no effect on growth (Boone, 1996), (Easlerly, 2003). Others have shown that aid has an effect on growth only when it is conditioned by "good policies" (Burnside and Dollar, 2000).

- Effects of ODA on education

Dreher and al. (2006), used panel data and a dynamic panel data estimator to assess the effects of aid on education through the rate of school attendance in underdeveloped countries. Using the primary school enrollment rate as a measure of educational outcomes, they show that aid has a robust and statistically significant positive effect on the primary school enrollment rate. They also show that, the quality of institutions does not have a robust effect on educational outcome. Michaelova and Weber (2006), use panel data and a dynamic panel data estimator to assess the effects of aid on education. They capture the education variable by the enrollment rate in primary school and the transition rate from primary to secondary. They show a small positive and statistically significant effect of aid on the primary school enrollment rate and the transition rate from primary to secondary school. They conclude that these effects are minimal enough to impact the economy. They also show that, policies and institutions in recipient countries matter a lot to the effectiveness of aid in education. 


\section{International Journal of Economics, Business and Management Research}

Vol. 6, No.01;2022

ISSN: $2456-7760$

Wolf (2007) and Gyimah Brempong and Asiedu (2008) studies also attempt to make the nexus between international aid and human capital formation. Both studies find a positive and significant effect for total education aid, but not significant for total aid. Rohen (2011), analyzes the impact of aid to education on educational achievement. The results show a positive and significant effect of aid to primary education on the net admission rate, the net enrollment rate, the net enrollment rate parity but not on the approximate completion rate and operating variables. Dreher and al. (2008) focus on primary education during the period 1970-2004. They use data on total aid to education committed as well as expenditure on education, all educational cycles combined, to explain the net primary school enrollment rate over a panel of 61 to 94 countries. The results seem to indicate a certain effectiveness of the aid to education for achieving UPE (Universal Primary Schooling), the effect being here also quite weak. Public expenditure on education does not appear to have an impact, as do the variables of governance and democracy. Masud and Yontcheva (2005) investigate whether external aid reduces poverty. In 76 countries, between 1990 and 2001, they find a significantly negative effect of education spending on the adult literacy rate. They also conclude that there is no significant impact of NGO aid per capita and bilateral aid per capita.

- Effects of ODA on health

Mishra and Newhouse (2007) conducted a study on the effects of earmarking for health on health. Based on a panel of 118 countries between 1973 and 2004, the authors find that aid earmarked for health significantly reduces infant mortality, but that its effect is rather weak: doubling health aid per capita is associated with a $2 \%$ reduction in infant mortality. They also conclude that total aid per capita does not have a statistically significant effect on life expectancy. Gyimah-Brempong and Asiedu (2008) also conduct GMM estimates on a panel of 90 countries with 3-year averages over the period 1990-2004, and find a significant negative effect of aid allocated to health on infant mortality. Chauvet and al. (2008), using data for 98 countries from 1987 to 2004, find that aid allocated to health is effective in reducing infant and child mortality, and that it is more so in the poorest countries. The study of Bokhari and al. (2007) is more particularly interested in the efficiency of public health expenditure on the health of populations, while taking into account the aid allocated to health, to control the effect of health projects from outside. Based on cross-sectional data for 127 countries in 2000, the effect of aid is estimated to be insignificant, regardless of the health indicator chosen (infant, child or maternal mortality rate). However, this effect is probably underestimated since the potential endogeneity of the aid is not addressed.

Wolf (2007) is more interested in the benefits of sector aid, both on health, on water and sanitation, and on education. Using cross-sectional data on 110 countries for 2002, the author shows that aid allocated to health significantly reduces infant and child mortality (but not infant mortality). Gomanee and al. (2005) have shown that total aid improves the Human Development Index (HDI) and reduces child mortality in PSDs. Verschoor and Kalwig (2006) show that aid increases spending recipient governments on social spending and increases the absolute elasticity of poverty and reduction of child mortality. 


\section{International Journal of Economics, Business and Management Research}

Vol. 6, No.01; 2022

ISSN: $2456-7760$

\section{Method}

\subsection{Dataset and descriptive statistics Variables}

- Level of education

We measure the outcome of education by the adult literacy rate. It is the percentage of the population aged 15 and over who can understand, read and write short statements about their daily life. Generally, literacy also includes the notions of arithmetic, that is, the ability to perform simple arithmetic operations. This indicator is calculated by dividing the number of literates aged 15 and over by the population of the corresponding age group and multiplying the result by 100 . Education outcomes should be measured in terms of the rate of education completion and quality measurement. The database does not have data on the quality of graduates. Only the quantitative dimension of the level of education is taken into account.

- Health level

Like Korachais (2010), we measure the level of health by the death rate. The crude death rate indicates the number of deaths during the year per 1000 people and is estimated at mid-year. We opt as a measure of the level of health, the crude death rate compared to other measures (life expectancy, morbidity rate, immunization), because there is very little reliable data in developing countries for other indicators such as life expectancy at birth or morbidity rates.

- Public Development Assistance

The variable of interest which is aid to health or education should normally be measured by the amount of aid allocated to the health or education sector; but in the absence of data, we will use the amount of overall aid, since aid, whether it is directed to any sector, has as its goal development and therefore the improvement of the standard of living and the well- therefore be the formation of human capital.

\section{- Gross Domestic Product per capita}

The gross domestic product per capita, (GDP per capita) is an indicator of the level of economic activity. It is the value of the GDP divided by the number of inhabitants of a country.

- Real Gross Domestic Product

Real GDP is a measure of the price-adjusted income flow generated by an economy, relative to the goods and services produced. It is a production-based measure.

- Education expenses

Public education spending (current and capital) includes public spending on educational institutions (public and private) and education administration as well as grants to private entities (students/households and others private entities).

- Health expenditure

This is the amount of the national budget allocated to the health sector. Health expenditure consists of expenditure made by: social security, the State and local communities, 


\section{International Journal of Economics, Business and Management Research}

Vol. 6, No.01; 2022

ISSN: $2456-7760$

complementary protection organizations (mutual societies, insurance companies, provident institutions) and households.

- DPT vaccination

DPT stands for "Dipteria Pertussis Tetanus"; it is a trivalent combined vaccine against diphtheria, pertussis, and tetanus, which are three infectious diseases.

- The ratio of doctors per 1000 inhabitants

According to the World Health Organization (WHO), a doctor is a graduate of an institution or a medical school that works in the field of medicine (practice, teaching, research). The indicator assesses their number per 1,000 inhabitants.

Our data is taken from the World Development Indicator (WDI) statistical database. The WDI database is the World Bank's first compilation of development data. It provides more than 869 development indicators and statistical series to date on 265 countries including several aggregates (groups of countries and income groups) since 1960. These indicators cover, by country, social areas (population, education, health, work, poverty and income), economic, financial as well as natural resources and the environment. It contains data published annually which allows the assessment of the development of many countries in the world.

\subsection{Model specification}

We use the econometric approach of the Generalized Method of Moments (GMM) with the efficient estimation of a dynamic panel proposed by Arellano and Bond (1991), Arellano and Bover (1995) and Blundell and Bond (1998). Panel data estimation techniques have several advantages. In addition to their ability to take into account the heterogeneity of units or individuals (such as the CEMAC countries in the context of this study), they provide more variability and precision, can take into account the influence of non-specific characteristics. They are observable, lead to less risk of multicollinearity among the variables, more degrees of freedom and more performance. These promote the study of the dynamics of change by making it possible to capture short and long term effects. The Generalized Moments in Difference method of Arellano and Bond (1991) is based on the first difference of the variables and thus eliminates the country specific effects while taking as instruments appropriate levels of lagged values (in level) for all potentially endogenous variables. In this model, the lagged values of the explanatory variables are weak instruments of the first difference equation. In addition, differentiating the level equation eliminates inter-country variations and takes into account only intra-country variations. Blundell and Blond (1998) following Arellano and Bover (1995) propose the system GMM estimator (Sys-GMM) which concerns the simultaneous estimation of the first difference equation associated with the level equation. Their model makes it possible to generate efficient dynamic panel estimators for analyzes over short periods. 


\section{International Journal of Economics, Business and Management Research}

Vol. 6, No.01; 2022

ISSN: $2456-7760$

\subsection{Estimation Strategy}

\section{Preliminary analysis}

Drawing on the work of Kwabena and Asiedu (2008), Dreher et al. (2006), Michaelowa and Weber (2006), Gupta et al. (1999), Bhalora (2007), Mishra and Newhouse, (2007), we propose a simple model where the dependent variables are education and health. We will capture education by the literacy rate. As for health, it will be captured by the death rate. We use data from the Word Development Indicator database. These data are analyzed by the Generalized Moments Method. The general shape of the model is:

$$
Y_{i t}=\alpha_{0}+\alpha_{1} o d a_{i t}+X \beta+\varepsilon_{i t}
$$

Where: $\mathrm{Y}$ is the result of education or health, aid is official development assistance, $\mathrm{X}$ is the regression vector that influences education or health, $\alpha_{0}$ and $\alpha_{1}$ are the coefficients to be estimated, $\varepsilon$ is the error term.

We capture education by the literacy rate. As for health, it will be captured by the death rate. The variables of interest are aid to education and aid to health. They will be measured by the percentage of ODA received per capita. The control variables for the education equation are: GDP per capita (GDPcapita), real GDP (real GDP) and education expenditure (Edex). The control variables for the health equation are: GDP per capita (GDPcapita), real GDP (real GDP), health expenditure (hex), "Diphteria Pertussis Tetanus" vaccination (VaccDPT), and the ratio doctor per 1000 inhabitants.

For the education equation, we have:

$$
E d u c_{i t}=\alpha_{0}+\alpha_{1} E d u c_{i, t-1}+\alpha_{2} \text { odacapita }+\beta_{1} G D P c a p i t a+\beta_{2} G D \operatorname{Pr} e a l+\beta_{3} e d e x+\varepsilon_{i t}
$$

Where: Educ $\mathrm{c}_{\mathrm{it}}$ is the education outcome, Educ $\mathrm{c}_{\mathrm{i}, \mathrm{t}-1}$ is the lagged education outcome, GPDcapita is the GDP per capita, GPDreal is the real GDP,edex is the education expenditure, odacapita is the Official Aid per capita and $\varepsilon$ is the error term.

Regarding the health equation, we have:

Txmort $_{i t}=\alpha_{0}+\alpha_{1}$ Txmort $_{i, t-1}+\alpha_{2}$ odacapita $+\beta_{1}$ GDPcapita $+\beta_{2}$ GDPreal $+\beta_{3}$ hex $+\beta_{4}$ vaccdpt + $\beta_{5}$ Ratiomed $+\varepsilon_{i t}$

Where: Txmort ${ }_{i t}$ is the result of health, Txmort $\mathrm{t}_{\mathrm{i}, \mathrm{t}-1}$ is the result of delayed health, GDPcapita is GDP per capita, Real GDP is real GDP, hex is health expenditure, Vaccdpt is vaccination "Diphteria Pertussis Tetanus ", Ratioméd is the doctor ratio per 1000 inhabitants, odacapita is Public Aid per capita and $\varepsilon_{i t}$ is the error term. 
International Journal of Economics, Business and Management Research

Vol. 6, No.01; 2022

ISSN: $2456-7760$

\section{Results and Discussion}

\section{Correlation test result}

Table 1: Correlation test in the first model

\begin{tabular}{llllll}
\cline { 3 - 5 } & Educ & GDPcapita & GDPreal & edex & odacapita \\
\hline Educ & 1.000 & & & & \\
GDPcapita & 0.692 & 1.000 & & & \\
GDPreal & 0.446 & 0.391 & 1.000 & & \\
edex & 0.5880 & 0.232 & 0.136 & 1.000 & \\
odacapita & 0.036 & -0.099 & -0.80 & 0.268 & 1.000 \\
\hline
\end{tabular}

\section{Source: Author's computation}

Table 1 presents the result of the autocorrelation test of the literacy rate and the variable of interest (odacapita) and the control variables (GDPcapita, GDPreal, edex). The first column and first row of the table presents the variables of model 1. The second column of the table presents the correlation of the literacy rate with the explanatory variables. All the coefficients in this first column being positive, we conclude that the literacy rate is positively correlated with GDP per capita, real GDP, education expenditure and Public Aid per capita. This means that, a change in real GDP, GDP per capita, education expenditure, and ODA will cause the literacy rate to change in the same direction. GDP per capita is positively correlated with real GDP, with health expenditure, but is negatively correlated with Official Development Assistance per capita. This means that a change in GDP per capita would lead to a change in the same direction in real GDP, in health spending. Real GDP is positively correlated with spending on education, but negatively correlated with Official Development Assistance per capita. Education expenditure is positively correlated with Official Development Assistance per capita.

Table 2: Correlation test in the second model

\begin{tabular}{|c|c|c|c|c|c|c|c|}
\hline & Txmort & GDPcapita & GDPreal & hex & Vaccdpt & RatioMed & odacapita \\
\hline Txmort & 1.000 & & & & & & \\
\hline GDPcapita & -0.5033 & 1.000 & & & & & \\
\hline GDPreal & -0.588 & 0.391 & 1.000 & & & & \\
\hline hex & -0.631 & 0.724 & 0.317 & 1.000 & & & \\
\hline Vaccdpt & -0.529 & -0.073 & 0.487 & 0.163 & 1.000 & & \\
\hline RatioMed & -0.631 & 0.599 & -0.013 & 0716 & 0.195 & 1.000 & \\
\hline odacapita & -0.110 & -0.098 & -0.080 & -0.065 & 0.194 & 0.020 & 1.000 \\
\hline
\end{tabular}

Source: Author's computation

Table 2 presents the result of the autocorrelation test of the variables used in model 2. The second column of the table presents the correlation of the mortality rate and of the variable of interest (odacapita) and of the control variables (GDPcapita, GDPreal, hex, Vaccdpt, Med Ratio). All the coefficients being negative, we conclude that the death rate is negatively correlated with GDP per capita, real GDP, health expenditure, vaccinations, the ratio of doctors 
per 1000 inhabitants and Public Development Assistance per capita. This means that a change in real GDP, GDP per capita, health expenditure, vaccination rate, ratio of doctors per 1000 population and ODA would lead to a similar change in the death rate.

GDP per capita is positively correlated with real GDP, health expenditure, and the doctor ratio per 1000 inhabitants; but negatively correlated with DPT vaccination and per capita Official Development Assistance. Real GDP is positively correlated with health expenditure and TPD vaccination, but negatively correlated with the doctor per 1000 population ratio and Public Aid per capita. Health expenditure is positively correlated with DPT vaccination and the doctor ratio per 1000 inhabitants, but negatively correlated with Public Development Assistance per capita. The DPT vaccination is positively correlated with the doctor ratio per 1000 inhabitants and the Public Assistance per capita. The ratio of Physicians per 1000 inhabitants is positively correlated with Public Aid per capita.

\section{- Effect of ODA on education}

Table 3: Estimation of the first hypothesis

\begin{tabular}{lll}
\cline { 3 - 3 } & & \multicolumn{1}{l}{ Model 1 } \\
\hline variables & Coefficients & $(\mathrm{z})$ \\
\hline Educt $\mathrm{t}-1$ & $0.970^{* * *}$ & 44.88 \\
GDPcapita & -0.0006 & -0.27 \\
GDPreal & $6.05 \mathrm{e}-11$ & 0.49 \\
Educ $\mathrm{t}$ & 0.047 & 1.07 \\
odacapita & $0.019^{* * *}$ & 2.69 \\
Sargan test & 86.16 & -0.098 \\
*** and ** denote significance at $1 \%$ and $5 \%$, respectively \\
\multicolumn{2}{l}{ Source: Author's computation }
\end{tabular}

Our analysis shows that our model 1 is globally significant at the $1 \%$ level. Regarding our variable of interest, which is ODA per capita, our results show that it is significant at the $1 \%$ level. Its coefficient being positive, and all other things being equal, an increase of one unit of ODA per capita leads to an increase of 0.019 point in the literacy rate. These results corroborate those of Kwabena and Asiedu (2008) who showed that aid has a significantly positive effect on the rate of enrollment in primary school and the rate of continuation of studies until the end of the primary cycle. This is also true for Rohen (2011) who shows a positive and significant effect of aid to primary education on the Net Admission Rate, the Net Enrollment Rate, the Net Enrollment Rate parity.

The probability of Sargan's test being less than $5 \%(\mathrm{p}=0.0000)$, we validate the lagged variable and conclude that the lagged literacy rate explains the model. The statistic is lower than the tabulated value, we do not reject the null hypothesis and we consider that the instruments are valid. Note that, the lagged variable is the one that contributes more to improving the literacy rate, followed by education expenditure, Public Development Assistance per capita, and finally real GDP. 


\section{International Journal of Economics, Business and Management Research}

Vol. 6, No.01; 2022

ISSN: $2456-7760$

\section{- Effect of ODA on health}

The results are shown in the table below.

Table 4: Estimation of the second hypothesis

\begin{tabular}{lll}
\cline { 3 - 3 } & & Model 2 \\
\hline variables & Coefficients & $(\mathrm{z})$ \\
\hline Txmort $t$-1 & $0.973^{* * *}$ & 106.73 \\
GDPcapita & $1.22 \mathrm{e}-06$ & 0.10 \\
GDPreal & $-1.32 \mathrm{e}-11^{* * *}$ & -4.34 \\
Healthexp & 0.0006 & 1.81 \\
Vaccexp & $-0.008^{* * *}$ & -10.72 \\
Ratio méd/1000capita & $0.241^{* *}$ & 2.04 \\
ODA/capita & $-0.0004^{* * *}$ & -3.17 \\
Sargan test & 216.77 & \\
*** and ** denote significance at $1 \%$ and $5 \%$, respectively \\
Source: Author's computation
\end{tabular}

Our table therefore presents the results of our second model. It can be seen that it is also globally significant $(\mathrm{p}=0.000)$. The variable of interest, which is always ODA per capita, is significant at the $1 \%$ threshold, and anything else equal to an increase of one unit of ODA per capita, results in a slight decrease of the crude death rate of 0.0004 point. These results corroborate those of Wolf (2007) who shows that aid earmarked for health significantly reduces infant and child mortality. This result corroborates that of Mishra and Newhouse (2007) who find that aid allocated to health significantly reduces infant mortality.

With regard to the control variables, health expenditure (hex) and GDPcapita are insignificant. The delayed mortality rate (Txmort 1 ) , the real GDP, the DPT vaccination (vaccdpt), and the doctor ratio per 1000 inhabitants are significant. Real GDP is significant at the $1 \%$ level; its coefficient being negative, all other things being equal, a one unit increase in real GDP leads to a $1.32 \mathrm{e}-11$ point decrease in the death rate. The sign obtained is in agreement with the expected sign. This result corroborates that of Korachais (2010), who shows that average income, adult education, public health expenditure per capita, play an important role in children's health. This is also true for vaccination, which is significant at the $1 \%$ threshold; its coefficient being positive and everything else being equal, an increase of one unit in the vaccination rate results in a decrease of about 0.008 point in the mortality rate, which is in agreement with the expected sign.

Regarding the doctor ratio per 1000 inhabitants (med ratio / 1000hbts), it is significant at the 5\% level; Its coefficient being positive and all other things being equal, an increase of one unit in the doctor ratio per 1000 inhabitants results in an increase of approximately 0.24 point in the death rate, which is contrary to the expected sign. This means that the doctor ratio per 1000 inhabitants does not explain the death rate in the CEMAC zone. There are several other supporting factors that are not taken into account for good physician performance; This may be the insufficiency or even the absence of technical platforms, the conditions for reaching health centers, etc. The delayed mortality rate is significant at the $1 \%$ level. The probability of the Sargan test being less 


\section{International Journal of Economics, Business and Management Research}

Vol. 6, No.01; 2022

ISSN: $2456-7760$

than $5 \%(\mathrm{p}=0.0000)$, we validate the lagged variable and conclude that the lagged mortality rate explains the model.

Our results are in agreement with several authors such as, Mishra and Newhouse (2007), Chauvet and al. (2008) and many others who have shown that aid has a positive effect on health.

\section{Conclusion and policy implications}

The objective of this work was to analyze the effect of the ODA granted in the CEMAC zone on access to education and health care. It emerges that the ODA granted in the CEMAC zone significantly increases the literacy rate in the CEMAC zone and that a variation in ODA, GDP, real domestic product and education expenditure, leads to a similar variation in the literacy rate. Likewise, an increase in ODA results in a small decrease in the death rate. A change in GDP per capita, real GDP, health expenditure, TPD vaccination rate and ODA would lead to a drop in the death rate. A change in public aid per capita will lead to a change in the DPT vaccination rate. An increase in aid will lead to an increase in the doctor-to-1,000 ratio, but that has no impact on the death rate.

The recommendations that can be made relate first and foremost to aid donors. They must be rigorous in verifying the application of the projects for which the aid is granted; direct aid to promising sectors, decouple aid from the negative impact of policy. As far as the recipient countries are concerned, they too must check the best use of funds and direct these funds towards important projects that help the population, manage aid without the influence of politics, provide for penalties for mismanagement aid, make aid managers aware of the proper use of these funds.

\section{References}

Arellano, M. et S. Bond (1991), « Some Tests of Specification for Panel Data: Monte Carlo Evidence and an Application to Employment Equations », The Review of Economic Studies, 58: 277-297.

Arellano, M. et O. Bover (1995), « Another Look at the Instrumental Variable Estimation of Error-component Models », Journal of Econometrics, 68: 29-51.

Bhalotra, S. (2007), "Spending to Save? State Health Expenditure and Infant Mortality in India", Health Economics, 16 (9), pp. 911-928

Blundell, R.S. et S. Bond (1998), «Initial Conditions and Moment Restrictions in Dynamic Panel Data Models », Journal of Econometrics, 87 (1): 115-143.

Bokhari, F.A.S., Y. Gai et P. Gottret, (2007),. "Government health expenditures and health outcomes". Health Economics, 16(3), 257-273.

Burnside, C. et Dollar (2000), "Aid, Policies and Growth", American Eco-

nomic Review, V ol.90, No.4, pp. 847-868.

Chauvet, L., F. Gubert et S. Mesplé-Somps, 2008. « Are Remittances More Effective Than Aid To Improve Child Health? » An Empirical Assessment using Inter and Intra-Country Data. Présenté à la Conférence $\mathrm{ABCDE}$ de la Banque Mondiale, Cape Town (South Africa), 2008. 


\section{International Journal of Economics, Business and Management Research}

Vol. 6, No.01; 2022

ISSN: $2456-7760$

Dreher A. , Nunnenkamp P. , Thiele R. (2008) : Does aid for education educate children? Evidence from panel data, World Bank Econ. Rev., 22 (2), pp. 291-314

Dreher, A., P. Nunnenkamp, and R. Thiele (2006), "Does Aid for Education Educate Children?" Evidence from Panel Data, Kiel Working Paper No. 1290, Kiel Institute for the World Economy.

Easterly, W. (2003), “Can Foreign Aid Buy Growth?”, Journal of Economic Perspectives, 17 (3), pp. 23-48.

Gomanee, K., Morrissey O., Mosley P., and Verschoor A. (2005), "Aid, Government Expenditure and Aggregate Welfare”, World Development, 33 (3), pp. 355-370. 15.

Gupta, S., Verhoeven M., and Tiongson E. (1999), "Does Higher Government Spending Buy Better Results in Education and Health Care?" IMF Working Paper WP/99/21.

Hansen, H., et Tarp, F. (2001). Aid and growth regressions. Journal of Development Economics, 64(2), 547-570.

Korachais C.(2010), « Contribution de l'aide publique au développement à l'amélioration de la santé dans les pays en développement »Sciences de l'Homme et Société. Université d'Auvergne - ClermontFerrand

Kwabena G.B.and Asiedu E.(2008), « Aid and Human Capital Formation: Some Evidence »

Masud N. et Yontcheva B. (2005), " Does Foreign Aid Reduce Poverty?" Empirical Evidence from Nongovernmental and Bilateral Aid.

Michaelowa, K. and A. Weber (2006), "Aid Effectiveness Reconsidered": Panel Data Evidence from the Education Sector, Hamburg Institute of International Development Working Paper No. 264.

Mishra, P. and D. Newhouse (2007), "Health Aid and Infant Mortality", IMF Working

OECD (2006), Development Co-operation Report. Volume 7, No. 1. Paris: OECD. ISBN 92-64$03651-2$

Rohen A. (2011), "Économie de l'éducation dans les pays en développement: Cinq essais sur l'aide internationale à l'éducation, la nature publique ou privée de l'enseignement, le choix des parents, l'efficience des collèges et la satisfaction des enseignants ", thèse de doctorat, Université d"eAuvergne, Clermont-Ferrand 1

Romer M. Paul (1990), “Endogenous technological change ”, Journal of Political Economy, vol. 98, n5, part 2, october, pp. S71-S102.

Smith, Adam (RN). 1976. An Inquiry into the Nature and Causes of the Wealth of Nations. Éd. de Edwin Cannan. Préf. De George J. Stigler. Chicago: The

University of Chicago Press, vol 1, 524p., vol 2, 568p.

Verschoor, A. and A. Kalwij (2006), "Aid, Social Policies and Pro-Poor Growth", Journal of International Development, 18 (4), pp. 519-531.

WHO (2001) : «Macroéconomie et Santé : Investir Dans la Santé Pour le Développement Economique », Rapport de la Commission Macroéconomie et Santé 
International Journal of Economics, Business and Management Research

Vol. 6, No.01; 2022

ISSN: $2456-7760$

Wolf, S., 2007. "Does Aid Improve Public Service Delivery?" Review of World Economics, 143(4), 650-672. 